\title{
El ardiente epílogo de Iluminaciones en la sombra de Alejandro Sawa. Para la desconocida historia del original de una obra representativa de la bohemia literaria española.
}

\author{
Juan Manuel González Martel ${ }^{1}$
}

Recibido: 11 de mayo de 2016 / Aceptado: 13 de diciembre de 2016

Resumen. Paradójica historia del original de Iluminaciones en la sombra, memorias de Alejandro Sawa (1862 - 1909), de la "literatura bohemia" española de comienzos del siglo XX. Libro póstumo, editado en 1910, de discutida adscripción a un género literario, combina la intimidad del relato de lo biográfico con los estilos del periodismo crítico. Es un texto que, a pesar de su descompensada estructura, revela aspectos de la vida y obra de su autor, reflejando, en su conjunto, la lucha ideológica de unos literatos bajo las débiles luces de bohemias de la sociedad española del tiempo.

Palabras clave: Alejandro Sawa; Miguel Sawa; Ramón María del Valle-Inclán; Rubén Darío; Iluminaciones en la sombra; literatura bohemia española; crónica periodística.

\section{[en] The ardent epilogue of Iluminaciones en la sombra of Alejandro Sawa. For the unknown history of the original of a representative work of Spanish literary bohemia.}

\begin{abstract}
Paradoxical history of the original Iluminaciones en la sombra, memoirs of Alejandro Sawa (1862 - 1909), Spanish "bohemian literature" of the early twentieth century. Posthumous book, published in 1910, of disputed ascription to a literary genre, combines the intimacy of the story of the biographical with the styles of critical journalism. It is a text that, in spite of its unbalanced structure, reveals aspects of the life and work of its author, reflecting, as a whole, the ideological struggle of some writers under the faint bohemian lights of the Spanish society of the time.
\end{abstract}

Keywords: Alejandro Sawa; Miguel Sawa; Ramón María del Valle-Inclán; Rubén Darío; Iluminaciones en la sombra; Spanish bohemian literature; Journalistic chronic.

Sumario: 1. Una reedición de Iluminaciones en la sombra y un recuerdo de la figura de Sawa. 2. ¿Un original de 400 páginas? ¿Cambios en el original de 1910? 3. Crónicas de "La Nación”, firmadas por Darío, en el libro de Sawa. Poirier recuerda a Rubén en 1952. 4. Una carta de Poirier ante lo que cuenta Luquero en 1951 5. Los originales 6. Una rebosante carpeta de recortes de prensa 7. El archivo de Sawa se divide. López Martín regaló a Hernández Luquero parte del "fondo literario". 8. Tras los papeles de Sawa 9. El original de Iluminaciones en la sombra A. Lo manuscrito en francés B. La colección de recortes de prensa 10. Un epílogo de fuego 11. Bibliografía

Cómo citar: González Martel, J. M. (2017). El ardiente epílogo de Iluminaciones en la sobra de Alejandro Sawa. Para la desconocida historia del original de una obra representativa de la bohemia literaria española, Revista de Filología Románica 34.1, 117-134.

Email: jmgmartel@hotmail.com 
Don Latino. - Yo he tomado sobre mis hombros publicar sus escritos. ¡La honrosa tarea! Soy su fideicomisario. [...]. Luces de bohemia, Escena última, 1920.

De por vida estoy unido al yunque de la letra impresa. [...] El veneno de los libros me embriaga como al morfinómano la morfina, como al alcohólico el alcohol. Y como a ellos me embriaga encantadoramente”. N. Hernández Luquero, "El Libro", Mundo Gráfico, 30.11.1921.

"Yo soy un hombre que de tanto mirar hacia la luz se ha quemado las pupilas", repetía Alejandro Sawa en sus últimos meses de existencia. Y Darío se hace eco de ese lamento, como final de su prólogo a Iluminaciones en la sombra, eligiendo la siguiente respuesta del escritor a una de las preguntas de un periodista que entrevistó a Sawa en Madrid en el verano de 1908. "Recuerdo de un hombre cuyas pupilas quedaron abrasadas por su afán de mirar fijamente a lo infinito". No imaginaron los lectores amigos que leyeron o quienes escucharon de viva voz esta queja, que tan retórica premonición incluiría Iluminaciones en la sombra; que la obra compuesta con la opinión y la memoria propia contenida en sus mejores textos, iba a estar sometido igualmente a irregulares e insuperables circunstancias editoriales y a cambios de propietario, como un libro destinado a prolongar la dramática leyenda bohemia de su autor.

Presentada la primera edición de Iluminaciones en la sombra con el crédito del prólogo de Rubén Darío y del "Epitafio. A Alejandro Sawa” de Manuel Machado, una evocadora semblanza y un sugestivo poema sobre el contradictorio destino del amigo fallecido, la obra ha sido valorada como uno de los mejores exponentes de la "literatura bohemia española", o "hispánica", por el crédito que desde 1910 le confirió el texto de Darío, testimonio del trato entre ambos modernistas.

El título, la fecha y las primeras frases de Iluminaciones en la sombra anuncian su carácter memorístico, pero su adscripción a un determinado género literario es uno de los asuntos discutidos. Y debido a su entramado, a modo de dietario, de unas prosas intimistas unidas a escritos de pura ficción y a crónicas, semblanzas, artículos, críticas..., van aflorando las dificultades propias de estos subgéneros en este conjunto de textos, de variado contenido, que habían sido publicados en prensa, de 1897 a 1908.

Alejandro Sawa, en el verano de 1908, para ilustrar las declaraciones hechas a Hamlet-Gómez para los lectores de Caras y Caretas de Buenos Aires, facilitó a este periodista amigo unas fotografías familiares y unas páginas de original del dietario que había concluido, Iluminaciones en la sombra, como quien tiene todo preparado para su publicación. Pero, la penuria económica y su débil salud impidieron que el ilusionado escritor español llegase a ver publicado el libro. Falleció en marzo de 1909.

Quince meses después serían editadas estas memorias, con el aval de un extenso prólogo de Darío, tal como se destaca en la cubierta de la edición. Una semblanza del literato que, como necrología evocadora, retrata varios aspectos de la personalidad de Sawa, pero en la cual apenas se razona sobre las particularidades de la obra.

No se conoce el original en su totalidad, lo que imposibilita las comparaciones textuales entre el original y su primera edición. Carencia que aumenta el número de dudas sobre el texto y de detalles pendientes de comentario. Así, continúan sin respuesta algunos extremos de estas memorias: unos, relativos a asuntos generales, 
como el número exacto de las páginas del original de Alejandro Sawa, y, otros, en relación con detalles menores, como las dataciones de crónicas, los nombres citados como referentes ya la autoría de ciertos textos.

En la bibliografía sobre Sawa apenas se ha mencionado el original de Iluminaciones en la sombra, del que únicamente se ha conservado una pequeña parte manuscrita, lo que apenas supone un quince por ciento del libro dispuesto por Sawa. Ni tampoco se sabe qué fue del manuscrito del prólogo de Rubén Darío del que dispuso la imprenta, cuya pista se pierde desde el mismo 1910.

¿Qué suerte corrió el resto del original de Iluminaciones en la sombra y el del prólogo? Como se ha tenido la convicción de que era documentación que no se había conservado, sin más, y como en verdad las referencias a tales originales eran mínimas, los investigadores que han manejado los papeles guardados por la familia siempre se han limitado a referirse a las 28 páginas manuscritas conservadas, en lengua francesa.

Se sabría algo más del original de Iluminaciones en la sombra si, en el conjunto de los papeles familiares, además de las conocidas páginas manuscritas, se hubiesen controlado la colección de recortes de prensa que se habían guardado en el hogar de Sawa. Tanto por haberla tenido como un conocido material impreso como por circunstancias familiares posteriores a la muerte de Sawa, esta colección fue desatendida, y, en una indeterminada fecha, fue regalada a un amigo de la familia y, medio siglo después, se vio afectado por un paradójico suceso, real epílogo de la desajustada historia editorial de Iluminaciones en la sombra.

A parte de la edición, distribución y venta que tenían los libros de la editorial, e independiente del reclamo del que particularmente gozase cada título de "Renacimiento", algunas circunstancias particularizan la historia de los originales y de los ejemplares de la Iluminaciones en la sombra.

\section{Una reedición de Iluminaciones en la sombra y un recuerdo de la figura de Sawa}

Una parte de lo impreso en 1910 pudo quedar sin encuadernar. Esos pliegos, como parte de los fondos de la imprenta, tras la crisis económica y cambio de propietario de la sociedad editorial, fueron reconsiderados por la nueva gerencia a finales de la década de 1920. Y se estimó que lo guardado de Iluminaciones en la sombra permitía convertirlo, con algún ligero cambio, como el de una nueva cubierta (que aparece incluso en las tiradas con la fecha de 1910), en una segunda edición. Aunque era título olvidado, se decidió que el recuerdo de la personalidad del escritor bohemio aún podría garantizar la comercialización de esa partida.

A los diez años de su muerte, sólo quedaba la difuminada imagen de Sawa como literato independiente, bohemios, in apenas obras. Y salvo la supuesta aproximación de Baroja (1911) y la excepcional interpretación de Valle-Inclán (1920-1924), nadie había intentado, con objetivo crítico, una revisión de la personalidad y obra de Sawa. Nadie se había interesado por los auténticos papeles de Alejandro, hasta que se decidió una reedición en 1929.

Esta nueva presentación del dietario de Alejandro Sawa fue impulsada por Fernando López Martín, casado con Elena Sawa Poirier. El yerno de Sawa, dramaturgo 
y poeta se tomó con empeño la reedición, pero no tuvo repercusión crítica. Y aunque la nueva edición de Iluminaciones en la sombra fue anunciada en 1929, en Ediciones Oriente $^{2}$, fue un trabajo que no terminó de consolidarse. El texto acabó pasando a la Colección EVA, de CIAP, con la significativa rareza de cambiar el 'Martínez' por 'Fernández' y colocarlo como primer apellido del autor: “A. Fernández Sawa”. Dos fracasadas ediciones vendidas con el mismo texto de la "Biblioteca Renacimiento".

La edición de 1929 era una simple reimpresión, eligiéndose la segunda cubierta, un dibujo que, sin embargo, aparece en ejemplares con la fecha de 1910. No se hizo corrección alguna y, por consiguiente, no hay ninguna diferencia textual. No se consultó la carpeta que contenía los artículos publicados que habían sido seleccionados para el original de Iluminaciones en la sombra.

La Esfera anunció, ilustrándolo con fotografía del escritor y la cubierta del libro, que "Acaba de publicarse Iluminaciones en la sombra", y reproduciendo el prólogo de Rubén Darío ${ }^{3}$, "cedido por el editor". Y en marzo 1930 el artículo de H. R. de la Peña, "Un gran señor de la literatura, de la palabra y del gesto. Alejandro Sawa", una entrevista a López Martín, que habla de Sawa, que fue ilustrado con dos reproducciones fotográficas: una imagen de Alejandro Sawa y del borrador de la polémica carta de Sawa a Darío. Se habló de las crónicas del encargo de Darío, la sustitución de firmas y, del grupo de documentos, releyéndose, como si fuera una auténtica novedad, la carta de reclamación que explicaba aquel enfrentamiento.

\section{2. ¿Un original de 400 páginas? ¿Cambios en el original para poder editar el libro en 1910?}

De Miguel Sawa, por sus excesivas responsabilidades -su propia familia, mujer e hija; su madre y hermana, la de su hermano Alejandro, viuda e hija, y los incontrolables Manuel y Enrique, el mayor y el menor de los Sawa-, hay que preguntarse en qué medida, ante el original de su hermano, pudo haberse impuesto algún tipo de censura a lo elegido antes de cualquier otro paso práctico relativo a la edición. ¿Alguna iniciativa con respecto a los contenidos?

Probablemente Miguel, a modo de censor familiar, apartó algún escrito sobre esas "esperanzas y tribulaciones" que apreció como intimidades que ya no venía a cuento descubrir. Y en lo material, ¿eliminó algunas crónicas que no le parecían las mejores de su hermano? ¿Asimismo, sobre qué cuestiones del texto consultó a Valle-Inclán: rogarle tal o cual control de la gestión con el editor o, un trabajo de imprenta o acuerdo sobre lo que se eliminaría?

Si se atiende a algunas afirmaciones sobre la extensión aproximada que pudo tener el original, entre las cerca de 400 páginas calculadas por Sawa -probablemente ésta es una estimación optimista- y las 255 páginas (formato: $18 \mathrm{~cm}$.), de la edición de 1910, y por muy diferentes que se plantee el recuento de esa diferencia de paginación, es margen entre el original y la edición que permite pensar en una reducción, apartando algunos textos ${ }^{4}$. Posiblemente se había acordado que la edición de "Bi-

Editorial madrileña, entre 1927 y 1931, dirigida por jóvenes intelectuales, especializada en libro social, preferentemente de "tendencia avanzada".

La Esfera, Madrid, 27.04.1929, pp. 32-33.

4 Dos fueron las cubiertas, en color: la dibujada por Marco (1910) y la dibujada por Augustus (1929). Sobre el 
blioteca Renacimiento", con la imprenta V. Prieto ${ }^{5}$ y C ${ }^{a}$ Editores (Pontejos, 8. Madrid), no sobrepasase, en la medida de lo posible, e las doscientas cincuenta páginas. El original debía reducirse, si bien la propia editorial, en sus catálogos resumidos pregonaba que sus volúmenes tenían de 250 a 400 páginas. Un acuerdo que, si bien se limitaría a la retirada de algunos artículos pudo alterar la posible estructura de la obra, en el caso de que la selección de artículos hubiese sido ordenada por Alejandro a modo de diario, con un espíritu temático determinado o como documento biográfico según contenido de los artículos.

Era un testimonio orientador unas anotaciones que se podían observa sobre los márgenes de los recortes de prensa de Sawa: la enumeración dada a la mayoría de los recortes de prensa. Los 145 artículos listados de Sawa es volumen que se acerca al número que compone la recopilación más amplia de artículos sawianos que se ha hecho, la de Emilio Chavarría (2008), si contamos los trabajos fechados a partir de 1897. Es decir, Sawa separó casi enteramente su obra periodística, hasta un ochenta por ciento, casi completa, porcentaje restante que se completa con ese veinte por ciento que pudo haberse descartado artículos alejados, por sus asuntos, de la línea temática pensada para su testimonial recopilación o por el íntimo carácter familiar.

Efectivamente, cuando se lee Iluminaciones en la sombra, ante ciertas particularidades de la organización de su contenido, se tiene la impresión de que entre el cierre del original decidido por Sawa a mediados de 1908, y el original que fue entregado a Renacimiento a finales de 1909, hubo cambios. Hay aspectos de la obra, relativos a la disposición textual de los contenidos que advierten de estos posibles cambios en el original de Sawa a la hora de su publicación. Y en espera de estudiarlos con tal exclusivo objetivo, apunto uno de los interrogantes que surge, por ser episodio conocido de la biografía de Sawa.

\section{Crónicas de "La Nación" firmadas por Darío en el libro de Sawa. Poirier recuerda a Rubén en 1952}

Se ha destacado la limitadísima mención de Darío en la obra póstuma de Sawa, e inevitablemente hay que preguntarse si se refleja en el libro el enfrentamiento del verano de 1908. Ya cerrado el original, ¿cuántas crónicas de las reclamadas por Sawa en 1908 incluyó en Iluminaciones en la sombra de 1910?; ¿en qué medida fue dispuesto por el propio Sawa la inclusión de algunas de las ocho crónicas -seis con título conocido- que había reclamado? O después de la muerte de Sawa, ¿los encargados de la edición comprobaron cuántas se recogían en el original? ¿Por qué Jeanne Poirier o Miguel, en correspondencia al favor de Rubén por haber escrito el prólogo que, no las apartaron? La obra editada contiene tres, de las ocho crónicas: la

motivo principal de una calle solitaria, nocturna, con línea de fachadas, a la derecha, con ventana iluminada, en una la calle solitaria y en otra una pareja de amantes, del brazo, que caminan por el centro de la misma. Se diría que ambas son interpretaciones de la realidad tanto del callejón de las Negras como de la calle Conde Duque. Augustus fue el ilustrador de la novela de Valle-Inclán Las reales antecámaras, de octubre de 1928 en la colección de "La Novela de Hoy".

Vid Esta noticia también la glosa Sergio Constán en su novedoso artículo sobre la carta de Sawa a Manuel Verdugo en 1908 (RFR, 33, 2016).

5 V. Prieto y $\mathrm{C}^{\mathrm{a}}$, en la calle Princesa, 77, quedaba muy cerca de los domicilios de la familia Sawa. 
de Ferrari, como nuevo académico de la RAE, y las dos sobre el anarquismo. Y, por otra parte, no descarto que alguna más, de las que Sawa no dio título, esté formando parte del texto de Iluminaciones en la sombra. ¿Por qué no se consideró necesaria tal deferencia con Rubén? ¿Despiste de los que manejaron el original o, por el contrario, se persistió en que tal inclusión fuese voluntario testimonio?

Unos ejemplares de Iluminaciones en la sombra vuelven a ser tenidos en cuenta a partir de1952. De regreso a Francia en 1916, hala en la década de 1950 de los ejemplares que guardaba todavía. ¿Cuándo volvió a París en plena guerra mundial, pensó en visitar a alguno de los antiguos amigos de Sawa? Ya nadie estaba en su sitio. No quedaba ninguno de los viejos compañeros. Ni siquiera Gómez Carrillo estaba en París.

Jeanne Poirier Mercier, que en marzo de 1951 había cumplido 80 años, vivía aún en Chatelet, en donde residía desde hacía años. Muerto su segundo marido, ya, inevitablemente, en los ratos de soledad y de dolencias, piensa en su propia muerte, en los gastos de enterramiento. De nuevo el tiempo había volado. No valía la pena recordar, pero, aparentemente todo se repetía ¡oh, cuánta dificultad! Ahora, como en 1909, iguales problemas para reunir, hacía poco, unas pesetas para unas discretas honras fúnebres de su marido como ahora, pensando en ella. Por entonces Jeanne estaba desprendiéndose de lo más valioso de sus cosas personales. Así lo notifica a sus nietos, ya que tanto Elena Sawa como su marido, Fernando López Marín, había fallecido. Les dice que lo que "me da mucha pena es que ustedes no los tengan". Pero, ique no se preocupasen!, para ellos, sus únicos nietos, tenía destinado, de lo que había conservado, lo más valioso, y lo de más fuerza sentimental, un anillo, que había sido de su marido Alejandro Sawa Martínez. Ya gestionaba, a través de una agencia de envío, la manera más segura de hacérselo llegar.

A pesar de las aprensiones de la edad, a Jeanne Poirier, viuda de Alejandro Sawa, que, después de haber vivido en España durante casi dieciocho años, y que había vuelto a su país en 1916, le quedaban aún unos cuantos años de vida, en los que, poco a poco, se fue reintegrando a su Borgoña natal, sus frecuentes cartas y con sus cortas temporadas provinciales en su región, con la familia de sus sobrinas pasaba algunas temporadas, en Charentenay.

En marzo de 1952, Jeanne Poirier recibió carta madrileña de sus dos nietos de su hija Elena, que habían adjuntado a su escrito un recorte de periódico de finales del año anterior: un artículo de NHL titulado "Una disensión literaria. Alejandro Sawa y Rubén Darío", de la revista Fotos, el 22 de diciembre de 1951" 6.

En la cita de Allen Phillips de esta carta hay un despiste que desorienta por la fecha que se consigna: 1915 por 1951, lo cual trastoca su significado contenido La simple referencia en la carta a "hace muchos años que ha muerto", refiriéndose a Rubén Darío, confirma que es de año muy posterior ${ }^{7}$.

A vuelta de correo, dos días después, Jeanne responde a su familia, fechando en "Chatelet, 15 de marzo de 51 [52]”, otra equivocación al consignar el año, más disculpable por la memoria y el reciente cambio.

Por la imprecisa caligrafía, la lectura de la fecha anotada es la de un día ¿13/15? de marzo de 1951. Un 1951 que, por error-despistado mimetismo con ese 1951 del

A parte del recordatorio que el artículo de Fotos, habían sido días en los que se habrían acordado más de su abuela, ya que el 18 de febrero se cumplió la fecha de la exhumación de Hélène Sawa: sus restos mortales pasaron a una sepultura de propiedad familiar.

Vid., Alejandro Sawa, mito y realidad (Madrid: Turner, 1976), p. 111. 
artículo de prensa de Hernández Luquero recibido en la carta de su hija que tenía delante-, es lo que consta en la respuesta que Jeanne envía de Chatelet a Madrid y que escribió a principios de ese mes de marzo de 1952. El artículo de Nicasio Hernández Luquero era de 22 de diciembre de 1951, por tanto, Juana se equivocó al datar su carta, por lo que realmente es cata es del mes de marzo de 1952.

Pero el interés de esta epístola - en hoja de papel cuadriculado, de formato escolar, $21 x_{13}^{\prime} 5$ cm.- se halla en el comentario familiar de Jeanne Poirier, tan vieja ya, a su hija, yerno y nietos sobre Rubén Darío tras la lectura de lo que recreaba Hernández Luquero de aquellas lejanas fechas de 1908 y de 1909. A pesar de los años transcurridos, de su inseguridad, del senil temblor de trazos, se reconocen los rasgos fundamentales de su equilibrada caligrafía que su firma pulso tenía en 1908.

\section{Una carta de Poirier ante lo que cuenta Luquero en 1951}

Se ha conservado en el archivo familiar, pero sin su final, puesto que el trozo de papel que contenía las líneas últimas se extravió. La presente transcripción refleja todos los extremos de la ortografía de Jeanne Poirier.

\section{Chatelet 15 Mar [19]51}

Mis queridísimos hijos ${ }^{8}: /$ Hace dos días que he recibido/ Sus carta y el articulo de/mi pobre Alejandro hablando/ De él y de Rubén Darío/ Hace muchos años que/ Yo lo conocía desgraciadamente/[S]éramos muy pobre y muy/ enfermo ciego y ese Rubén/ muy egoísta no se acordaba/ de el pobre/ cuando yo le avisado que/ estaba muerto me contestó/ así: que él no pasaba/ nunca en donde ella pasaba\%/ Bien ha pasado sin querer/ Hace muchos años que se ha/ Muerto pero cuando fui/ haberle para pedirle el/ Prólogo gracias a Dios me/ recibió muy bien sin embargo/// no era fácil abordarle/ a[ir]empentado seguramente/ de lo que había echo con/ mi pobre Alex/ Carmencita ${ }^{10}$ no lo ha leído en/ Su libro póstumo (Iluminaciones/ en la sombra) eso si es/ precioso. Los libros ${ }^{11}$ los tienen/ Prospera Raposo [en] Nicolás Leblanc ${ }^{12} / 16$ si ustedes tenían alguno/ que vallan a Paris ${ }^{13}$ podrán/ traérselos son

8 Dice "hijos" dirigiéndose a sus dos nietos, Alex y Fernando, y a su nieta política, Carmen Calleja, mujer de este último, que se había casado antes que el mayor.

9 Jeanne Poirier confirma con este comentario -al igual que otros testimonios en este sentido de amigos del nicaragüense-, lo que también se atribuye a Miguel Sawa sobre Darío, según Ramón Gómez de la Serna: "Rubén Darío [...] envió a Miguel Sawa una carta en que decía, lleno de temor a la Muerte: "No voy a la casa, porque no quiero ir donde está Ella".

10 Carmen Calleja Roveta se casó en 1947 con Fernando López Sawa. Falleció en 2015.

11 Referencia a parte del saldo de Iluminaciones, a los posibles ejemplares de la primera edición que Jeanne pudo llevarse consigo a Francia en 1916 o a los que le pudo enviar Fernando López Martín, su yerno, de la segunda edición de 1929.

12 A este amigo de Jeanne Poirier, Próspero Raposo -16, rue Nicolás Leblanc- Carmen Calleja identifica a este vecino de Jeanne: "a través de él llegamos a enviar algunos regalos o dinero. Nosotros escribimos a Raposo"). Se vuelve a nombrar a Raposo en carta de 20 julio, s. a. Ella estaba entonces en Charentanay, por una temporada; Raposo se lo envía desde París: "Ayer yo he recibido vuestro regalo, como dicen ustedes, pero Raposo no me dice si es tuyo, mi querido Fernando y Carmencita, o de Alex". Raposo era muy amigo de su segundo marido de Jeanne, también español. Así pues, en el piso de Raposo en París se guardaban ejemplares de Iluminaciones en la sombra.

13 Poirier, después de unos años en París, había vuelto a residir en su región de nacimiento, Borgoña. 
a vuestra dos-/ posición/// Hijos de mi vida, el tiempo/ es mucho mejor, pero con/ el pinten tengo una Broncita/ tres cortes el medico me dice/ que no tengo nada tanto vieux/ yo lo espero. Tú me recomendé/ de guardar el artículo, pues/ no hija mía será mejor en/ vuestras manos guárdalo bien/ es muy bonito y dice muchas/

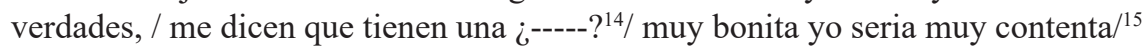

Una escueta vocación, de vejez y de tono familiar, que remite al agradecimiento escrito de Jeanne a Rubén en diciembre de 1909 cuando recibió el prólogo, y que sugiere, entre otras consideraciones, que aquella equilibrada carta le fue escrita y ella se limitó a pasarla a limpio y enviársela a Rubén Darío.

\section{Los originales}

De los originales de Iluminaciones en la sombra se sabe poco. Falta de documentación al respecto. No hay suficientes referencias en el epistolario de las personas relacionadas con los Sawa ni en la crítica del tiempo.

No se conoce lo sucedido con el manuscrito del prólogo. E ignoro si es asunto estudiado por las últimas investigaciones, y que ese documento se conserve, sin más, en poder de algún afortunado propietario, ya sea un particular o una institución.

Cuando Darío avisó a la familia de Alejandro Sawa de que ya tenía terminado el prólogo que Jeanne Poirier le había solicitado personalmente, fue recogido inmediatamente en el domicilio de Rubén y entregado a la imprenta. Y na vez editado el libro, es de suponer que también la semblanza hecha por Darío, como parte del original, igualmente fuese devuelta por la editorial, puesto que el original la obra figuró, después de 1910, entre los papeles del escritor.

No hay noticia, por otro lado, de que fuese devuelto a Darío. No consta registrado en el archivo de Rubén Darío, en los papeles nicaragüense en Madrid. Si Poirier no lo regaló a algún conocido, a alguien que se lo solicitases a ella directamente, declarándose admirador del poeta, estarían entre los papeles de Miguel Sawa.

Realmente esas páginas manuscritas, consideradas por algunos como una de las excelentes muestras de la prosa del poeta nicaragüense, tuvieron que haber estado junto con el original de Iluminaciones en la sombra que tenía la familia López- Sawa.

\section{Una rebosante carpeta de recortes de prensa}

No se tiene noticia alguna de cuándo o cómo fue devuelto el original de Iluminaciones en la sombra.

Miguel sabía sobradamente lo que aquel libro que se iba a editar había supuesto para su hermano. Sawa había proyectado un diario, tal como lo había tanteado desde 1901, pero igualmente contemplaba su idea como la reunión de lo más representativo de sus escritos, aquellos que revelaban mejor su posición ideológica frente a su entorno social; unas confidencias que hilvanaría con crónicas, narraciones, semblan-

Se trataba de un perrito, según Carmen Calleja.

15 Las líneas fundamentales de esta carta, de la línea 1 a la 26, fueron publicadas por Allen Phillips. 
zas..., con todo lo que, en suma, apreciaba más de las reflexiones contenidas en sus mejores artículos, del estilo de sus prosas.

A lo largo de 1908, Sawa había apurado sus contactos personales para la publicación de la obra, cuyo sumario definitivo cerró al final de la primavera. Entre sus papeles, hay testimonios de esas primeras gestiones con editores de Madrid y Barcelona. Pero pronto se desengaña, comprendiendo que las contestaciones de casa editoriales eran muy evasivas, $\mathrm{y}$, por lo tanto, que lo más conveniente era pensar en una edición por su cuenta, en imprenta madrileña de su confianza.

Pero el verano se echa encima. Y aquella última fantasía de imaginar a Darío como definitivo apoyo se esfuma. Pero leerá con disgusto lo de "Como supongo que tu libro se publicará en otoño, cuando yo vuelva a Madrid entonces, tendré mucho gusto en contribuir junto con los demás amigos, a la edición de tu libro". Y su impaciencia se acelera y, dos semanas de julio son suficientes para que sus ilusiones se estanquen y, furioso, vuelve a reconsiderar la situación, arremetiendo contra todo lo que le parece que contradice sus aspiraciones. La esperanza en Darío, una de sus frustraciones. Y pasa al ataque, inútilmente. Parecía tenerlo todo dispuesto. Había optado "casi con seguridad" por la imprenta de los hijos de Márquez, imprenta que le había presupuestado una tirada de tirada de dos mil ejemplares, las urgencias se fueron imponiendo y el dinero reunido solucionó otras necesidades, las de medicación y la manutención. No se pudo publicar el libro. Y lo acabado, en los últimos meses de su vida quedó relegado ante la urgencia que impusieron su maltrecha salud y empobrecida economía.

Entre los conocidos más comprensivos pervivió la idea de que a Sawa, olvidados sus méritos, se le reprochaba que fuese "fiero y público denostador de los editores, admirable desdeñador de las intrigas periodísticas. Algunos lectores amigos hallaron en Iluminaciones en la sombra el eco perdurable de tanta y tan injusta afrenta" (Cristóbal de Castro, 1918). Para otros, la confirmación de un vano orgullo y de una limitada capacidad literaria.

Finalmente, no consiguió que se la publicasen, ni él pudo pagarse la edición de la obra. Un fracaso del que fue consciente, obsesivamente, hasta marzo del año 1909, días en los que sus desvaríos terminaron sumiéndolo en la locura.

A la muerte de Sawa el original de Iluminaciones en la sombra podía haber permanecido en la carpeta que lo contenía junto a los otros papeles del escritor. Dejaba una obra póstuma: fue el comentario entre las amistades cuando acaeció su fallecimiento. Del día del óbito es el testimonio de Valle Inclán a Darío, su propuesta: "Alejandro deja un libro inédito. Lo mejor que ha escrito. Un diario de esperanzas y tribulaciones".

Pasados unos meses, aunque frenada la gestión, persistía la idea de la edición de la obra como una obligación pendiente con el fallecido y una iniciativa que podría remediar algo la precariedad económica de la viuda e hija ${ }^{16}$. Y finalmente, llegada la hora de impulsar la tarea, la "venta del libro" se concretó con la "Sociedad Editorial Española"17, propiedad de Miguel Moya.

Con la intermediación de Jeanne Poirier, la mujer de Alejandro Sawa, en la edición de Iluminaciones en la sombra, fueron Miguel Sawa, hermano del escritor, y

16 Los precios con los que se suele marcar esta primera edición en el actual mercado del libro viejo y antiguo hubieran sacado de apuros al autor...

17 El trust al que pertenecía una serie de publicaciones periódicas españolas, a partir de 1906. "El Liberal" fue de los diarios liberales más representativos de este grupo. 
Ramón María del Valle Inclán, quienes, como fraternales albaceas, se comprometerán a sacar adelante el libro de Alejandro. Retomaron -según las pocas noticias conocidas- lo que Sawa había dispuesto como original, siendo sus decisiones las que primaron: las de Miguel, como principal interesado y, entre los conocidos, las de Valle Inclán, en quien el hermano de Alejandro depositó su confianza en los meses en que estuvo en Galicia.

Miguel, el único apropiado para controlar enteramente los trabajos editoriales, tuvo que repartir, con sus comentarios directos o por carta, tareas y recados. Hacía unas semanas que había aceptado la dirección de La Voz de Galicia de A Coruña. Y de su correspondencia, algunas noticias se refieren a la edición, si bien son detalles que tienen más que ver con las condiciones en que debería hacerse el contrato o con la venta del libro que con las particularidades de su contenido.

El lograr un prólogo de Rubén -quizá idea alentada por Valle-Inclán- había sido un objetivo último y principal. La importancia del poeta garantizaba el prestigio de la edición y, por tanto, favorecía su divulgación y venta. Y conseguido, en efecto, se decidirá que el nombre de prologuista fuese en cubierta.

A mediados de 1910 se dispuso de los primeros ejemplares de Iluminaciones en la sombra. Y en la primera semana de julio los que habían colaborado habían recibido el libro. La tirada tendría una aceptable venta, si bien quedaron en el almacén de la imprenta, encuadernados o en pliegos, una cantidad indeterminada de ejemplares; y en poder de Jeanne Poirier otra parte para a fin de que pudiese venderlos o regalarlos.

\section{El archivo de Sawa se divide. López Martín regaló a Hernández Luquero parte del "fondo literario"}

Si el original no fue directamente devuelto a la familia de Sawa, a su mujer, y, por alguna circunstancia estuvieran en manos de Miguel Sawa, después de su temprana muerte, cuando la familia revisó sus papeles, es posible que los referidos exclusivamente a Alejandro fueron devueltos a su cuñada. Ahora, como de manera más drástica ocurriera años después, en vísperas de la Guerra civil, mucha de la documentación, aun la considerada indispensable, por miedo, fue eliminada por las respectivas familias de Alejandro y Miguel. En el caso de Miguel, la desconfianza ante la imagen progresista del republicanismo radical que María Palacio consideraba tenía su marido la impulsó a eliminar mucho de lo que Miguel guardaba.

Finalmente, el original estaba en manos de Jeanne Poirier, y por muchos años. Unos documentos de los que pudo disponer, lógicamente, Fernando López Martín, yerno de Sawa ${ }^{18}$.

Pocas habían mencionado, familiarmente, a Alejandro Sawa en las décadas de 1930 y 1940. Pero hubo excepciones como Manuel Machado y Nicasio Hernández Luquero, poeta y articulistas. Pero, de los dos, Luquero fue el amigo de confianza para Fernando, con antes de la guerra, había tenido siempre la oportunidad de hablar de "don Alejandro".

Muerto en 1945, el poeta y dramaturgo, represaliado, no volvió a publicar después de la caída de Madrid. Hasta su fallecimiento fue vigilado. Las dificultades económicas no lo rindieron ni el continuo control político. 
La carpeta de Iluminaciones en la sombra, había permanecido en poder de los López-Sawa. Pero en una revisión de papeles, la familia decide quedarse únicamente con la parte manuscrita, y el resto, compuesto por recortes de prensa, en fecha anterior a 1936, fue regalado por López Martín a su amigo Nicasio Hernández Luquero, poeta y periodista castellano. El mismo Luquero lo confirmó en 1974: "tengo la fortuna de poseer el fondo literario del gran prosista, datos sobre su vida, en sus postreros días aperreada y triste, y su perfil humano, tan singular y atrayente".

Agradecido por su fidelidad a la evocación de su suegro. Fernando, y que era hombre generoso, regaló efectivamente al arevalense los recortes de prensa que le parecieron menos personales y que el amigo podría aprovechar para su trabajo periodístico. Y fallecido Fernando, sus hijos recordaban haber escuchado a su padre decir que una parte de los papeles, "muchos artículos", se los había dado a Hernández Luquero.

\section{Tras los papeles de Sawa}

Desde comienzos de la década de 1960, la labor de los nietos de Sawa por reconstruir la memoria del abuelo, y poder reeditar alguna de sus obras, fue alentada por los artículos de don Nicasio, quien persistía en la evocación de Sawa ${ }^{19}$. El abulense, que ya en 1909 y, luego, a partir de 1951 había escrito sobre Alejandro Sawa, lo tenía al corriente de cualquier referencia a su abuelo que encontraba en sus lecturas, y de las cartas y visitas que recibía de estudiosos que, enterados de la existencia de esos papeles, se interesaron por la huella de Sawa. Así le comunicó la curiosidad que manifestaba una serie de estudiosos de la literatura española.

Notificada por la prensa, la parada en Arévalo de Díaz-Plaja, a la vuelta de un viaje académico a Salamanca, para saludar a Hernández Luquero, a fin de poder hablar con él sobre el magnífico prosista desaparecido Alejandro Sawa, sobre el que se hacen actualmente profundos estudios críticos. Hernández Luquero posee el archivo que perteneció al escritor, de todos los trabajos periodísticos en la prensa de España de Sawa [...] encontraron respuesta a los proyectos que traían" (palabras del cronista local para El Diario de Ávila [y] para que éste le ofreciera datos sobre el magnífico prosista desaparecido Alejandro Sawa. Hernández Luquero posee el archivo que perteneció a él en relación con los trabajos periodísticos de la prensa española de Sawa" (El Norte de Castilla).

López-Sawa, en la década de 1960, no logró disponer de la colección de recortes en la biblioteca de Hernández Luquero. Con los papeles propios y con los datos de su investigación particular, se había convertido en indirecto informante de las muchas preguntas que se le hacía, por carta o en entrevista particular. Buscaba información, como un afanado estudioso de la biografía de su abuelo, puesto que en los documentos heredados apenas había documentación para satisfacer sus curiosidades. Los que eran inéditos los había extraído de la correspondencia de su abuela materna, Jeanne Poirier.

Con respecto a lo que supuestamente guardaba Hernández Luquero, López-Sawa pasó de pensar que su amigo podría tener una documentación que completaría la

19 Los artículos sobre Sawa son posteriores a la muerte de López Martín: 1951, 1956, 1967, 1971. Y en una de sus últimas crónicas, al calor de las conversaciones mantenidas con el hijo, hizo una semblanza del poeta y dramaturgo "Fernando López Martín" en El Norte de Castilla. 
suya, a convencerse de que nada de lo que pudiese haber regalado su padre a don Nicasio tuviese gran interés, salvo el mejor control de y fichado de la colección de recortes originales de los artículos de prensa. Y su trato con Luquero continuó, intensificándose en la década de 1970. Al menos seis veces lo visitó Fernando en Arévalo a don Nicasio.

Otro estudioso, desde los tiempos de su preparación de su estudio sobre las Sonatas de Valle Inclán, Zamora Vicente fue configurando un paulatino asedio a los esperpentos. Desde 1961, con "Releyendo Luces de bohemia", en Ínsula), como resultado del viejo interés por Valle Inclán (desde 1949, y divulgado como colaboración en La Nación de Buenos Aires, "Evocación del esperpento",), escora hacia las circunstancias biográficas de Sawa. Y como ajuste de su investigación valleinclanesca contactó con Hernández Luquero, pero no hubo consulta de los documentos de los que disponía el poeta.

López Sawa asistió a la recepción académica de Zamora Vicente en 1966. Escuchó el discurso "Asedio a «Luces de bohemia», primer esperpento de Ramón del Valle-Inclán” y, como generosa deferencia al nuevo académico, le facilitó una reproducción de parte del archivo de Sawa, al igual que se lo facilitó a Dicenta cuando proyectó la semblanza de Sawa, apartado de La Santa Bohemia (1976). A ambos regaló una reproducción del retrato de Paul Verlaine ${ }^{20}$.

La novedad siguiente la constituye las propuestas de dos editoriales de la década de 1970, por iniciativa de sus directores literarios (Nicasio Salvador Miguel, Santos Sanz Villanueva, José Caballero Bonald) y las investigaciones de José F. Dicenta, o Iris M. Zavala ${ }^{21}$ o Allen W. Phillips en la década de 1970.

Todos detrás de esa colección de prensa preparada por Sawa, nadie más que don Nicasio los había repasado. Porque lo que conservaba Hernández Luquero era lo directamente recibido de la familia madrileña: la carpeta de Iluminaciones en la sombra. Por consiguiente, enterados de que en la localidad abulense de Arévalo podría haber documentación inédita de Sawa, intentaron consultar dichos papeles. Pero, fuere en visita personal o por carta, aparte de la sugestiva charla o la prosa epistolar del escritor castellano, que continuaba en sus artículos evocando las letras de sus tiempos, aseguraba que únicamente poseía "unos recortes de artículos".

Hernández Luquero tuvo la posibilidad de releer cómodamente gran parte de las crónicas de Sawa y algunos recortes de críticas. Y a partir de entonces, con el viejo crédito de su "Alejandro Sawa, muerto", de 1909, en la que, con discreto respeto y detalle, recreó el velatorio en la mañana del 4 de marzo de 1909, habría de manejar una amplia información que sobre Sawa y su tiempo, sumando su verdadera experiencia y testimonio de gente y situaciones, la crónica de don Nicasio, así pues, se enriquecía al tocar estos asuntos no sólo con el recuerdo de Sawa y esa memoria de la época sino también con detalles releídos en la vieja carpeta $^{22}$.

20 J. F. Dicenta regaló su copia a F. Umbral. Y Zamora Vicente me regaló la suya.

21 Con posterioridad, y entre los últimos que pudieron consultar lo principal de ese Archivo, antes de que, tras frustrada subasta, fuera adquirido por la Residencia de Estudiantes en Madrid, están los profesores Pura Fernández -que estudió especialmente la correspondencia íntima de Jeanne Poirier con Alejandro- y Amelina Correa Ramón, autora de la última y excelente biografía de Alejandro Sawa; y el escritor Andrés Trapiello, quien desde muy pronto se interesó por las particularidades del dietario del sevillano en el ámbito de los diarios en las letras hispánicas.

22 En una ocasión, primera, aseguró que, no obstante, que nunca había llegado a tratar al escritor. Pero en artículo 
A los investigadores que se interesaron por esos recortes, Hernández Luquero no les mostró nunca el contenido de la carpeta. ¡En algún lugar de la gran biblioteca de la casona de la recoleta Plaza de la Villa estaba mal colocada! Y algún que otro investigador regresó de Arévalo, después de una visita que había imaginado prometedora, despistado. No mentía don Nicasio diciendo que eran solo recortes de prensa. Un extravío bibliotecario real o el cuidado bibliográfico de Luquero por la figura del maestro, con su intención de continuar escribiendo sobre él, o su avanzada edad, no lo animaban a poner la carpeta en manos ajenas. Y así el montón de recortes de prensa, aparte de releerlos y de entresacar algún que otro asunto de crónica, siguió en estante de la biblioteca del arevalense.

A raiz de su discurso de entrada en la Real Academia Española, Zamora Vicente fue animado a publicar una edición crítica de Luces de Bohemia, y a la aceptada elaboración de notas del texto de Valle-Inclán se combinó con el proyecto de anotar el texto de Iluminaciones en la sombra. Pero sus acuerdos definitivos con Clásicos Castellanos tardaron en fijarse, y la idea del libro de Sawa fue relegada. El trabajo como secretario interino de la Real Academia mermó su tiempo de investigación. En 1973, los directores literarios de Retorno Ediciones y Ediciones Júcar fueron los primeros en interesarse por la reedición de Iluminaciones en la sombra. Pero las propuestas no prosperaron.

La primera editorial había solicitado a Iris M. Zavala un estudio preliminar. La edición fue anunciada en el catálogo de 1973-1974. Pero, solicitado esa introducción en 1973, la edición de Iris M. Zavala de Iluminaciones en la sombra (fechada en Nueva York, 1972-1974), se editó y estuvo en librería a mediados de 1977, ya con el cambiado sello editorial de Alhambra ${ }^{23}$. Zavala trabajaba en ese tiempo también con su "Fin de siglo: modernismo, 98 y bohemia", para Cuadernos para el diálogo (1974).

Finalmente, el estudio se completó y la edición se hizo: "Reproducimos la edición única [1910] de esta obra, corrigiendo algunas erratas y nombres extranjeros mal escritos". Concluyó que "El texto de Iluminaciones en la sombra la obra entraña, sin embargo, enigmas", considerando que le parecía "imposible afirmar con exactitud la fecha definitiva de su composición", en relación con las fechas aludidas en la obra, 1901, 1903-1907, si bien en las notas se remite a algunos textos fechados en 1897. Y, en dichas notas, recurrirá sobre todo a las colaboraciones de Alejandro Sawa en Helios y Don Quijote. Mas esta edición no se planteó problema textual alguno, ni con respecto al original de Sawa ni a la edición de $1910^{24}$ y lo que los pocos datos novedosos sobre Sawa que se manejaban procedían principalmente de la información cedida por Fernando López Sawa. Y éste facilitó la consulta de las páginas manuscritas de Iluminaciones en la sombra existentes en su archivo. Pero, no dispuso de lo de Hernández Luquero.

Paralelamente, Allen W. Phillips, que se había interesado por Valle Inclán en la década de 1960, entre sus contactos para su investigación sobre Sawa, contó inicial-

de 1971, con ocasión del estreno de Luces de bohemia, afirma que "Yo conocí y traté a Alejandro Sawa", y en otro de 1974, "Yo conocí a Sawa en la Redacción de La Lucha", que dirigieron sucesivamente Joaquín Dicenta y Eduardo Zamacois". Y otros artículos de Nicasio Hernández Luquero: "La muerte de Max Estrella", El Norte de Castilla, 1971.- "Alejandro Sawa, un olvidado", ABC, Madrid, 22.05.1974.- "Tiempos viejos de la bohemia literaria", $\mathrm{ABC}$.

23 Se autorizó la editorial, en 1978, para ceder gratuitamente los derechos de la obra a la asociación americana Recording for the Blind, de New York, para su grabación en cinta magnetofónica, con destino a los ciegos.

24 La tirada fue de 4.000 ejemplares. 
mente con el trato de Zamora Vicente, quien le presentó, a Fernando López Sawa ${ }^{25}$. En poco tiempo, reunió los datos suficientes. Y uno de los últimos viajes de Fernando a Arévalo fue para acompañar a Allen W. Phillips, regresando con la impresión, como no vieron papel alguno, de que Hernández Luquero no poseía otra documentación que no fuese unos recortes de prensa.

Tras la muerte de Hernández Luquero el 4 de octubre de 1975, su hija Aurora, el día 8, comunicó a Fernando la noticia: "Es posible que cuando recibáis estas líneas ya sepáis la triste nueva...". Y únicamente ocho años y medio después, en 1984, fue cuando su única heredera prestó a Fernando la carpeta. Contenía únicamente "recortes de prensa", pero, al fin, en esa visita a Arévalo, volvía Fernando a Madrid con parte de los papeles de Sawa que pertenecían al poeta castellano. La decisión Aurora satisfacía la curiosidad del nieto de Sawa.

López Sawa pudo confirmar que en la carpeta no había ninguna fotografía ni documento familiar, ni referencia alguna a otro tipo de noticias biográficas. Asimismo, observó que se trataba, como lo había asegurado Hernández Luquero, de un montón de recortes. No había ningún papel autógrafo, salvo las notas manuscritas repartidas en algunos artículos de prensa.

No hubo tiempo para estudiar detenidamente la colección de crónicas que guardaba Hernández Luquero. La muerte sorprendió a Fernando López Sawa justamente en días en que había estado ocupado con una primera ordenación de esas crónicas procedentes de Arévalo, anotando, de puño y letra, alguna particularidad. Y sólo alcanzó a comunicarle tales impresiones a Zamora Vicente. La carpeta permaneció entre sus papeles hasta que Calleja de López-Sawa, recuperadas las tareas interrumpidas, cumplió con la palabra de su marido de devolverla. Ella misma la entregó en mano en Arévalo, "una rebosante carpeta marrón”, a Aurora Hernández-Luquero. Poco después, Carmen Calleja, se animó a pedirlos de nuevo, en 1999, temporada en que tuve ocasión de repasarlo, pero el rápido requerimiento, a los pocos meses es, de Aurora Hernández Luquero, que estaba revisando aún en 2000 el legado paterno, su patrimonio, su biblioteca. No hubo apenas tiempo para tomar algunas notas sobre el estado y disposición y de lo más legible de lo escrito sobre los recortes. Prometió que, en cuanto se hiciese tal trabajo, otra vez se los dejaría. Pero cuando, después de un tiempo, Calleja decidió pedirlos nuevamente, la idea no prosperó. ¡La carpeta, una vez más, se había colocado mal entre tanto libro de la biblioteca! No aparecía la carpeta. Unos cinco mil volúmenes, bien seleccionados, con una mayoría de ediciones recibidas de la mano de sus autores, era lo estimado de aquel fondo bibliográfico reunido en Arévalo.

\section{El original de Iluminaciones en la sombra}

Con respecto a la edición de 1910, uno de sus intereses se centra, como se ha adelantado, en las diferencias que pudo haber entre el original decidido exclusivamente por Sawa y lo que resultó ser, por diversas circunstancias, el texto de 1910, es decir, lo que finalmente fue entregado a la imprenta. Y, tras esa primera edición, lo que se constata es que las nuevas ediciones repiten el texto de ésta. No se contó con toda la

25 Vid. Zamora Vicente, A. "Los papeles de Alejandro Sawa”, La Razón, Madrid, 7.04.1999. 
documentación heredada. La colección de recortes existente hubiese podido relacionarse con el original de Iluminaciones en la sombra.

En realidad, aquellos recortes anotados, que fueron regalados a Hernández Luquero, constituían una gran parte del original de Iluminaciones en la sombra. Unos recortes, desordenados, que no figuraban en la edición de la obra de 1910, ni en las siguientes, $\mathrm{p}$ ero que habrían podido haber formado parte de un posible original $\mathrm{y}$, finalmente, aparatados. Algunos, numerados y con notas, indicaban que habían sido organizados con alguna otra finalidad.

\section{A. Lo manuscrito en francés}

Las páginas manuscritas en lengua francesa se corresponden con el inicio del libro, $\mathrm{y}$, aunque con ligeras variantes, a lo publicado en español a modo de diario en Alma Española, Helios o Renacimiento Latino. Y a este comienzo se debe el que se haya escrito, como se lee en la edición de Iris M. Zavala en 1977: "El manuscrito francés que guarda la familia López de Sawa", Hay que precisar que se trata de "las páginas manuscritas en lengua francesa que coinciden con las primeras páginas del texto de Iluminaciones en la sombra (1910), pero no tienen por qué ser ni el resto de un manuscrito en lengua francesa ni el comienzo manuscrito mixto, que comenzase en francés y que continuará en castellano. Y estas páginas manuscritas originales habían sido publicadas antes de 1909 .

Separado del resto de los papeles se guardaba, dentro de una solapilla titulada Rayons dans l'ombre unas páginas manuscritas:

Extensión: Veintiocho páginas: cinco, de $13^{\prime} 5 \times 20 \mathrm{~cm}$., y veintitrés páginas, de $15,5 \times 21 \mathrm{~cm}$.

Manuscrito: Las 23 páginas, a una cara, escritas en francés, corresponden, a su vez, a las 35 primeras páginas de la edición de 1910, al texto impreso que va desde el comienzo del diario hasta el segundo párrafo de la página 36. Y escritas en español, 5 páginas -dos de las cuartillas, por ambas caras-, sobre la muerte de Paul Verlaine, el apartado igual que el de la edición.

\section{B. La colección de recortes de prensa}

Con el reseñado manuscrito, el original de Iluminaciones en la sombra había un conjunto de recortes seleccionados por Sawa entre los que constituían su colección de artículos de periódicos y revistas publicados.

Aunque la mayoría fueron redactados y publicados entre 1900 y 1908, algunas de las crónicas elegidas son de fecha anterior.

Habitualmente, cuando le publicaban algún artículo, Sawa guardaba el correspondiente recorte. Lo releía y si hallaba alguna errata o algo mejorable lo corregía sobre la marcha. No obstante, algunos de ellos fueron retocados en lecturas siguientes, cuando los reeditó o en ese tiempo en el que estuvo centrado en la elección de los que compondrían Iluminaciones en la sombra.

Por consiguiente, el grupo de crónicas elegido fue convertido en original, como si se tratase ya de una prueba impresa. Las correcciones, las sustituciones y las notas 
hechas por Sawa en esos recortes eran, en la práctica, como como la última prueba del original.

Por lo general, las rectificaciones introducidas, tras su publicación en prensa, suelen ser precisiones o cambios en las de las referencias culturales, literarias o artísticas; sustituciones de vocablos, con el fin de evitar exceso de repeticiones; sustituciones o precisiones léxicas en busca de acepciones semánticas más precisas; o nuevas adiciones de palabras o expresiones de distinta índole, etcétera, si bien, en mayor proporción, lo enmendado sean detalles morfosintácticos: artículos, posesivos, demostrativos, preposiciones, sustantivos y adjetivos, etc.

Estos recortes de prensa, como colección o como conjunto de crónicas para el libro, fueron sometidos a una ordenación, tal como parece indicar la numeración que consta en la mayoría de los recortes, al modo de un fichero general. Un ordenado repertorio de donde entresacó los artículos para Iluminaciones en la sombra o aquellos otros que volvió a publicar en prensa. Y fue una disposición hecha desatendiendo la fecha de redacción o de publicación. Y tampoco esa ordenación está ceñida estrictamente al orden que presenta la Iluminaciones en la sombra. Su número se indica en el margen superior del recorte, izquierda o derecha del margen, dentro de un círculo, son 150. Y un reducido número de estos que no fue anotado con un número.

Algunos recortes contienen anotaciones, manuscritas, que puntualizaban: el nombre de la publicación de la que procedían; la fecha; circunstancias particulares de su génesis; cambios de título, etcétera. Lógicamente algunos cambios, por ser su letra, tuvieron que ser hechos cuando aún Sawa tenía condiciones físicas para hacerlas personalmente, por lo que algunas de las correcciones fueron introducidas en los artículos cuando fueron reconsiderados para editarlos en prensa.

La edición de Iluminaciones en la sombra era una realidad textual desde 1910, fuesen muchos, pocos o ninguno los cambios realizados sobre el original de Alejandro Sawa.

\section{Un epílogo de fuego}

De Madrid a Arévalo. Las vivas impresiones de anteriores recorridos castellanos, con ineludibles paradas en localidades de Ávila; y siempre en Arévalo, un rico sitio histórico de pujante actividad. Y ahora, un nuevo viaje, con el exclusivo fin de volver a cruzar una recoleta plaza, por delante de la casa del poeta Nicasio Hernández Luquero, en cuya biblioteca a menudo se habló y escribió sobre Rubén Darío y Alejandro Sawa.

Aquella noticia de Arévalo recibida en diciembre de 2001 no terminaba de olvidarse a pesar del tiempo transcurrido. El suceso sigue recordándose, aunque sean pocos los que conocían de los pormenores de lo ocurrido en esa fecha en ese lugar del norte de Ávila.

Corrió la voz, al igual que el fuego estaba devorando una vivienda del centro de la villa. Y los arevalenses vieron cómo el incendio consumía la casa del poeta Nicasio Hernández Luquero. "Tú la paz de esa plaza castellana" era el primer verso de uno de sus poemas.

Durante toda la desapacible noche el siniestro mantuvo en vela a los vecinos. Un cortocircuito había sido la causa. La casona del erudito literato, con su magnífica bi- 
blioteca, ardió durante horas. Se estaba perdiendo, además de los enseres familiares, el patrimonio bibliográfico y artístico del escritor castellano, uno de los tesoros de la región. "Hay algo de ceniza en el ambiente", era el inicio de otra de sus poesías.

Extinguido el fuego, a la hora del primer recuento de lo perdido, nadie mencionó lo que allí había registrado del escritor Alejandro Sawa. Pocos lo sabían. Entre lo desaparecido, papeles relacionados con el bohemio andaluz. En esos primeros recordatorios, nadie recordó que entre lo guardado había una colección de recortes de artículos con gran parte de los cuales se había compuesto el original del libro póstumo de Sawa.

Y de regreso del corto viaje, por los pocos kilómetros, la cercanía con la localidad de Navalsauz, donde estuvo largo tiempo celosamente respetada la documentación de Rubén Darío.

Con el fuego, en aquella biblioteca de Arévalo, se perdía la oportunidad de reconsiderar el libro a la luz de muchas de las indicaciones anotadas por el autor en esos recortes. E igualmente era ceniza lo que el poeta pudiese haber tenido de otros documentos de los Sawa, con lo que menguaba la posibilidad de conocer con mayor exactitud la posición del escritor ante su propio original. Y aunque mucho de lo apuntado en esos papeles fue atendido en la corrección en la edición póstuma de 1910, un repaso más detenido del original perdido habría permitido un mejor conocimiento del texto de Iluminaciones en la sombra. Y esa información, entre otros beneficios, hubiese equilibrado el desacuerdo de la crítica: para algunos, un texto heterogéneo, anárquico, misceláneo o descuidado, en relación con asuntos, disposición y fechas; para otros, una selección de obra propia con una distribución ajustada para la cual el autor ideó una ordenación.

En 2001, recibida la noticia, tras minutos de silencio, qué se podía remediar todavía. ¿Las notas tomadas, con urgencia, en su momento, sin intención de que fueran exhaustivas, podrán servir de algo? Las repasaremos.

Y lo sucedido influyó, con una drástica decisión, en la pequeña historia del archivo de origen de los documentos perdidos. En 2002 su propietaria, tras desatendidas propuestas de venta a varios organismos y, luego, una fallida subasta, sin concurrencia alguna, la heredera decidió vender el archivo que conservaba en Madrid. La heredera consideró que su edad no le permitía otra medida más adecuada para la seguridad de la documentación restante ${ }^{26}$. Y desde entonces es propiedad de la Fundación Residencia de Estudiantes, en Madrid.

Un paradójico epílogo, a centenario cumplido de la muerte de Alejandro Sawa y de la publicación de su obra póstuma. Ribetes de una descuidada historia y de la creciente leyenda de un destino bohemio en las letras españolas de comienzo del siglo XX.

Una detenida y extensa carta personal, inédita, de la última propietaria, Carmen Calle de López Sawa, fallecida en 2015, cuenta su versión de este quiebro último de los papeles de Alejandro Sawa. 


\section{Bibliografía}

Castro, Cristóbal de. (1918): “Alejandro Sawa". La Novela Corta, Año III, n 135, Madrid, agosto, 1918.

Chavarría, Emilio. (2008). Edición e introducción a: Alejandro Sawa. Crónicas de la bohemia. Madrid: Veintisiete Letras.

Constán Valverde, Sergio. (2016).’De Alejandro Sawa a Manuel Verdugo: noticia de una carta olvidada. Revista de Filología Románica, vol. 33, n 2, 223-235.

Correa Ramón, Amelina. (2008). Alejandro Sawa, luces de bohemia. Sevilla: f)L Fundación José Manuel Lara.

Dicenta, José Fernando. (1976). La santa bohemia. Madrid: Ediciones Centro.

Ena Bordona, Ángela. (2013). "Revisitando Iluminaciones en la sombra de Alejandro Sawa". Journal of Hispanic Modernisme, issue 3-4, 39-58, 2013.

García, Alberto. "Iluminaciones en la sombra de Alejandro Sawa". Educaguía.com.

González Martel, Juan Manuel. (2006). "La amistad de Alejandro Sawa y Ramón Valle-Inclán en el Archivo de los Sawa (1862-1984)", Madrygal, 9: 78-79.

Phillips, Allen W. (1966). "Sobre la génesis de Luces de bohemia", Ínsula. n. o 236-237, julio-agosto de 1966, 9.

. (1968). "Sobre Luces de bohemia y su realidad literaria”, Ramón del Valle Inclán. An Appraisal of his Life and Works. Nueva York, 1968, 601-614.

. (1967). "Rubén Darío y Valle-Inclán: historia de una amistad literaria", Revista Hispánica Moderna, XXXIII. núms. 1-2, enero-abril de 1967, 1-29.

Sawa, Alejandro. (1910). Iluminaciones en la sombra. Prólogo de Rubén Darío. Biblioteca Renacimiento. Madrid, Imp. Prieto y Cía.

. (1929). Iluminaciones en la sombra. Biblioteca EVA. Madrid: Compañía Iberoamericana de Publicaciones.

. [s.a.]. Iluminaciones en la sombra. [¿Córdoba?]: Ediciones Oriente.

(1977). Edición, Estudio y Notas de Iris M. Zavala.

. (2004). Presentación de Andrés Trapiello. Madrid: Josef K. Editor.

. (2009). Prólogo de Andrés Trapiello. Madrid: Nórdica Libros.

Sawa, Miguel. (2010). Historias de locos. Introducción de Sergio Constán Valverde. Sevilla: Renacimiento.

Vidal, Fabián. (1910). “Crónica. Un libro póstumo”. La Correspondencia de España, Madrid, 7.07.1910.

Zamora Vicente, A. (1978). "Más sobre el contorno de Luces de bohemia", en Estudios ofrecidos a Emilio Alarcos Llorach... Oviedo, Universidad de Oviedo.

. (1967). Asedio a Luces de bohemia, primer esperpento de Ramón del Valle-Inclán. Madrid, Gredos.

(1969). La realidad esperpéntica. Madrid: Gredos.

Zavala, Iris. (1986). Iluminaciones en la sombra. Estudio preliminar: Madrid: Alhambra. . (2008). Alejandro Sawa. Crónicas de la bohemia. Estudio e I. M. Zavala. Introducción de Emilio Chavarría. Madrid: Veintisiete Letras. 